\title{
The production of safe foods
}

\author{
A. C. BAird-PARKer \\ B.Sc., Ph.D. \\ Unilever Research Laboratory, Colworth House, Sharnbrook, Bedford
}

\begin{abstract}
Summary
This article summarizes the steps that a food producer takes to ensure that bacterial food poisoning risks are minimized. These include microbiological control of raw materials, processes and the final products. The importance of good process control as the best means of reducing the food poisoning risks is emphasized.
\end{abstract}

\section{Introduction}

Previous speakers at this Symposium have dealt at some length with the bacteria and toxins that cause bacterial food poisoning and chemical and dietary problems associated with modern foods. In my contribution I want to indicate how a large food manufacturing company approaches the problem of minimizing the risk of bacterial food poisoning resulting from its products.

As food manufacturers we accept the moral and legal responsibility of selling foods which are, as far as is technically possible, free from all food poisoning hazards in accordance with the U.K. Food and Drug Act 1955 . This places a heavy responsibility on the many quality control and development bacteriologists in our operating companies who run the quality control programmes required to give this assurance. We, in research, and the development department bacteriologists, in our operating companies, aid our factory quality control bacteriologists by providing them with the best possible techniques for analysing foods for food poisoning bacteria and also with the design of safe food processes. Research also provides data on means of destroying food poisoning bacteria in foods; on the product formulations and the packaging and storage conditions required to prevent bacterial growth.

The assurance of minimal risks of bacterial food poisoning depends on the food manufacturer having control of raw material supplies and processing and packaging conditions relevant to the distribution and sale of a particular food. Control of foods during distribution is also very important in minimizing food poisoning risks but I will not consider this aspect.

\section{Control of raw materials}

Let us first consider the raw materials. The control of these is of prime importance in any factory quality control programme. We control the microbiological quality of our raw material by a programme of visits to suppliers' factories, vigorous but realistic microbial specifications for raw materials, and by an ongoing raw materials quality control programme in our factories. We find that suppliers of raw materials who have poor control of their processes, and whose management does not accept the need for quality control programmes, are unlikely to produce the consistently high quality raw materials that our factories require. Our company bacteriologists or standards officers visit suppliers and on the basis of their reports and samples of raw materials submitted for laboratory evaluation decide on whether a contract should be placed. Not infrequently bacteriologists from our operating companies will make a working visit to a supplier's factory to investigate $?$ reasons for unsatisfactory bacteriology results. It is very important that a supplier fully understands the reasons for our requirements. We find that this understanding leads to better co-operation between the supplier and the operating company. Where appropriate, before a contract is finally placed, a microbial specification is drawn up. The supplier may also be provided with complete details of the microbiological methods that will be used to monitor his products. This is necessary as it is usually found that the methods used by suppliers give an inaccurate assessment of the microbial content of their products.

It is difficult to generalize on the details of a microbial specification for a raw material (Jay, 1970). This will depend at least on a knowledge of any further processing that the raw material may be subjected to in our factories as well as the composition, shelf life and storage conditions of the final product. Thus, for a raw material that is not further processed by our factories, such as an ingredient for a dry soup mix, we may require a supplier to meet microbial limits for anaerobic and aerobic mesophilic bacteria as an indication of the overall quality of raw materials and processing. Also we may specify a coliform limit as an index of general hygiene of processing and an Escherichia coli limit as an indicator of possible faecal contamination. We will also specify limits for specific food-poisoning bacteria such as 
Salmonella, Clostridium welchii and Staphylococcus aureus.

For an ingredient that is used for a thermallyprocessed low-acid canned food, e.g. a meat or vegetable soup, we will be more concerned with the bacterial spore content of the materials used for the canned product than with the presence of specific bacteria. However, we will include in specifications requirements for the total bacterial load, in order to avoid processing materials that may have been abused by the supplier and thus spoiled on receipt at our factories. Also we may stipulate that if for reason of supplying a particular raw material, the supplier subjects the raw material to a cooking procedure, the supplier should check for the presence of Staph. aureus before cooking. We do this to avoid the possibility that Staph. aureus has multiplied and formed its heat resistant enterotoxin in an ingredient before cooking, resulting in absence of Staph. aureus cells in the final product but possible presence of enterotoxin. Our standards are in general based on a knowledge of microbial limits which are achievable in products produced under good manufacturing conditions.

Sampling rates that are used to ensure that a particular ingredient meets our standards will depend principally on a knowledge of whether that ingredient is likely to be a problem. We usually ask our suppliers to supply ingredients to a particular standard or microbial limit, e.g. Grade A. We accept, however, that because of the general inaccuracy of microbial count procedures perfectly acceptable raw materials, produced under good manufacturing conditions, may apparently have levels of micro-organisms which are just outside our Grade A standard or specification. Thus we may ask our suppliers to meet the Grade A standard for at least $90 \%$ of their production and to meet a Grade B standard in no more than $10 \%$ of their production. The difference between a Grade A or B standard for most recorded counts will be $5-10$ fold. We use a similar grading procedure to control production in many of our factories. We do not allow this flexibility in our standards to affect our limits for a critical organism such as Salmonella when the limit will be the same for our A and B Grades. A product which is outside Grade $B$ is rejected and if the proportion of product outside Grade A but inside Grade B increases we take this up with our supplier.

We are not completely happy with the microbial quality of all our raw materials. However, we are to some extent dependent on the problem that a supplier may have in finding high quality, pathogen-free raw materials. Thus it is at present impossible to find a producer of raw chicken meat or pork who can always meet a Salmonella standard requiring absence of Salmonella in, for example, a $25 \mathrm{~g}$ sample.
In most of our manufactured products these ingredients are cooked during processing and it is therefore our responsibility to take all the necessary precautions to avoid cross contamination, etc., during processing. However, with many raw products we can only produce end-products that are as free from Salmonella as the raw materials.

It may be possible to reduce Salmonella contamination significantly by dipping carcasses in very hot water before butchery, but this cannot be used for many meat products. We can also incorporate sodium metabisulphite in certain of our cereal-containing comminuted meat products in the U.K. This certainly helps to reduce Salmonella multiplication in mishandled products as well as reducing the growth rate of the more numerous spoilage organisms. Without the addition of metabisulphite it would be impossible to market the traditional fresh British sausage in many parts of the country, as the shelf life of the product would be very short in retail outlets without exceptionally well controlled chill cabinets. It would appear that the potential food poisoning problem caused by the presence of Salmonella in raw poultry and red meats will only be solved by avoiding all possible routes of contamination during the life of the animal. The complete solution will certainly be long term and although efforts to avoid the contamination of animal foods with Salmonella are now being made in this country by animal feed products, this is only part of the problem as Salmonella is not infrequently endemic in poultry stock and animal herds. It is also difficult to eliminate all possible sources of Salmonella contamination from the environment. Complete avoidance of Salmonella in our foods must inevitably lead to increased cost of food products. A better approach to the Salmonella problem, at least in the short term, is to educate the consumer how to handle raw meat products without exposing his or her family to a risk of food poisoning.

\section{Control of processing}

Having considered the control of raw materials let us now consider the microbiological control of the food manufacturing process.

Process control is one of the best means that the food manufacturer has of controlling the microbial quality and safety of the products he manufactures. Of the available process controls, heating still remains one of the simplest and best means of destroying undesirable bacteria in our raw materials. Thus, since the introduction of pasteurization of raw milk, ice-cream mixes and liquid egg there has been a marked decline in food poisoning outbreaks involving dairy and bakery products. Similarly, except where very poor processing control has been shown to be a fault, there have been no botulism outbreaks 
involving commercial canned foods since the principle of the 'botulinum cook', i.e. a thermal treatment designed to destroy $10^{12}$ spores of $\mathrm{Cl}$. botulinum, was adopted internationally by the canning industry (Ingram, 1969). The degree of heat processing required to destroy food-poisoning bacteria in foods is one of the most studied aspects of food microbiology. The degree of heat treatment required to render a food microbiologically stable, i.e. unable to support the growth of pathogenic or spoilage microorganisms, will depend on the composition of the food and whether preservatives such as nitrite are present as well as the normal temperature of storage. Thus products such as canned fruits, hams, salamitype sausages, salted-fish delicacies or sweetened condensed milk, which are unable to support the growth of $\mathrm{Cl}$. botulinum, are rendered microbiologically safe and stable by heat treatments which are substantially below that required for canned soups and uncured meat products.

For the production of non-thermally processed foods it is important to operate all processes at the economically lowest possible temperatures. The lower the temperature, the slower the growth of all pathogenic and spoilage bacteria. Thus by running processes at low temperatures the food manufacturer can run processing plants for longer periods between sanitation and has a much better microbiological control over his production. Approximate times for running plant between clean-up and sanitation are established by laboratory investigations. Actual times are obtained by microbiological investigations during plant commissioning.

In setting up a food processing line it is necessary for bacteriologists to work alongside engineers and planners responsible for machinery layouts to make sure that all plant coming in contact with food can be cleaned and sanitized. It is also important that plant and personnel processing raw products are physically separated from plant processing and packaging final products. A further point is the control of the direction of any airflow from air conditioning plant, etc., such that cross contamination of clean final products from dirty raw materials, etc., is prevented.

In our experience, and, I am sure that of other food manufacturers, many designers of food processing equipment never really consider the need to be able easily to clean and sanitize a piece of equipment. This is usually a problem that the factory bacteriologist ends up solving by expensive and extensive modifications. We are attempting to influence the hygienic design of food-processing equipment by studying the best hygienic design of vessels, pumps, valves and pipe joints, etc., for use in food processing plants. We find that the most easily cleaned and sanitizable plant is not necessarily the most expensive.
It is much cheaper to consider all problems relating to cleaning and sanitizing plant before a food processing plant is built and installed rather than to try to modify a plant that is ill-designed from these aspects.

Having set up a process, and written operating manuals for the process, it is necessary to train and educate the staff responsible for running the plant in the basic principles of hygiene and plant control. This, together with the training of a team responsible for maintaining the hygiene of the plant, is a further job that our company bacteriologists undertake. We find that by giving suitable talks on hygiene to all levels of management and staff responsible for processing we can significantly improve the general microbiological quality of our products. Our companies actively employ medal inspections, antiseptic soaps and sanitizers aimed at the maintenance of food safety.

The company bacteriologists are also responsible for drawing up programmes to maintain and control the hygiene of our processes. This is usually done by selecting a series of points in the process which can be sampled to monitor that the processing is satisfactory from the bacteriological point of view. These are called 'Critical Control Points' (Atkin, 1972). In a simple processing situation such as the pasteuriza-tion of milk or liquid egg the satisfactory functioning of the process can be established by the use of an enzyme test such as the phosphatase test for milk or the $\alpha$ amylase test for liquid egg; absence of cross contamination can be checked by a coliform test. The functioning of a sterilization process, such as is used for canned products, is checked by accurately recording process times and temperatures, checking chlorination levels in cooling water and checking that can-seaming is correct. For non-thermal processes it is necessary to monitor product temperatures and to do microbiological tests on samples taken from established 'Critical Control Points'.

\section{Control of product}

Our food products are usually distributed chilled, frozen, dried or canned; some containing permitted preservatives may be distributed at ambient temperatures in plastic or aluminium foil packs. The final stage in our microbiological quality control programme is to check that the food product leaves our factory in a satisfactory microbiological condition. For safety we check that the products meet microbiological limits for specific food poisoning bacteria; this may be retrospective for fresh meat products which cannot be stored while awaiting microbiolgical clearance. Such microbiological limits are based on what public health opinion in the many different countries in which we sell food considers to 
be a level at which there is no concern as to a health hazard (Hausler 1973; Foster, 1969).

We also check that the proposed packaging and/or distribution system for a food will not lead to a health hazard if it is mishandled during distribution or in the hands of the consumer. We do this by checking for absence of growth of food-poisoning bacteria, including $\mathrm{Cl}$. botulinum, in selected products. Studies are also done to establish the defrost life of frozen foods. Based on these studies we establish the shelf life and write instructions on the pack advising the consumer how to store, cook and handle a food such that it reaches the table in the best possible condition.

\section{References}

Atkin, L. (1972) Prevention of contamination of commercially processed foods. In: Proceedings of the 1971 National Conference on Food Protection. U.S. Department of Health, Education and Welfare: Food and Drug Administration USA. (FDA 72-2015).

FosTER, E.M. (1969) Bacteriological standards for foodstheir significance. Journal of the Association for Food and Drug Officials, 33, 119.

HAUSLER, W.J., JR (1973) Legislation and non-legal specifications. In: The Microbiological Safety of Food (Ed. by B. C. Hobbs and J. H. B. Christian), p. 387. Academic Press: London and New York.

INGRAM, M. (1969) Spore formers as food spoilage organisms. In: The Bacterial Spore (Ed. by G. W. Gould and A. Hurst), p. 549. Academic Press: London and New York.

JAY, J.M. (1970) Modern Food Microbiology. Van Nostrand Reinhold Company: New York. 